\title{
Pricing Chinese Convertible Bonds with Dynamic Credit Risk
}

\author{
Ping Li and Jing Song \\ School of Economics and Management, Beihang University, Beijing 100191, China \\ Correspondence should be addressed to Ping Li; lipingxx@126.com
}

Received 14 March 2014; Accepted 23 May 2014; Published 9 June 2014

Academic Editor: Chuangxia Huang

Copyright (C) $2014 \mathrm{P}$. Li and J. Song. This is an open access article distributed under the Creative Commons Attribution License, which permits unrestricted use, distribution, and reproduction in any medium, provided the original work is properly cited.

\begin{abstract}
To price convertible bonds more precisely, least squares Monte Carlo (LSM) method is used in this paper for its advantage in handling the dependence of derivatives on the path, and dynamic credit risk is used to replace the fixed one to make the value of convertible bonds reflect the real credit risk. In the empirical study, we price convertible bonds based on static credit risk and dynamic credit risk, respectively. Empirical results indicate that the ICBC convertible bond has been overpriced, resulting from the underestimation of credit risk. In addition, when there is an issue of dividend, the conversion price will change in China's convertible bonds, while it does not change in the international convertible bonds. So we also empirically study the difference between the convertible bond's prices by assuming whether the conversion price changes or not.
\end{abstract}

\section{Introduction}

Convertible bond is an innovative and complex financial instrument which can be converted to the issuer's stock at some specified circumstance. It is hard to be valued because of its characters of both equity and bond, in addition to its varieties of terms. China's convertible bond market is an emerging market, so it is important to value the product considering some changes compared with the existed valuation methods.

Theoretical research on convertible bonds was initiated by Ingersoll [1], who applied the Black-Sholes-Merton model of pricing options. Following his work, Brennan and Schwartz [2] firstly used corporate value as the basic variable to price convertible bonds. However, corporate value was soon replaced by stock price for its simplicity of observation and measurement, which was first introduced by McConnell and Schwartz [3]. Brennan and Schwartz [4] considered stochastic interest rate firstly and constructed a two-factor pricing model for convertible bonds. Then, stochastic credit risk was introduced by Davis and Lischka [5]. From the above tendency we can see that researchers gradually added factors to increase the accuracy of valuation. To solve the more and more complex models, Monte Carlo simulation became widely used. Longstaff and Schwartz [6] firstly introduced the least squares Monte Carlo (LSM) to price American options. Following them, Moreno and Navas [7] studied the robustness of LSM method for pricing American options;
Stentoft [8] studied the convergence of the LSM approach. Due to its significant advantage in pricing derivatives, LSM method was soon applied to the valuation of convertible bonds, such as the work of Crépey and Rahal [9] and Ammann et al. [10].

Credit risk is an important factor in convertible bonds valuation and is paid more attention than before in China. Currently, there are two methods to measure the credit risk. The first one is credit spread, which is firstly used by McConnell and Schwartz [3] to value convertible bonds. Following their work, Tsiveriotis and Fernandes [11] split convertible bond into two components: a cash-only part, which was discounted by risky interest rate, and an equity part, which was discounted by risk-free interest rate. The second method is to use default density, which was used by Duffie and Singleton [12] to price corporate bonds. Then, Ayache et al. [13] applied default density to convertible bonds, deriving a partial differential equation for valuation. Comparing the two methods, the first one is more widely used for its simplicity and convenience. However,the estimation of the spread is essential.

To get more accurate price, researchers began to employ dynamic credit risk. Davis and Lischka [5] supposed that hazard rate obeys a Brownian motion, with the Vasicek model of interest rate, and then established a two and a half model. But they did not verify the effect of the model using real data. 
Currently, there is not any model applying dynamic credit risk to price convertible bonds. In addition, when there is a distribution of dividend, the conversion price will change in China's market, while it does not change in the international market. In this paper we will study the pricing of China's convertible bonds using dynamic credit risk and then empirically study the difference between the prices obtained by assuming whether the conversion price changes or not.

The rest of this paper is organized as follows. Section 2 gives the basic framework of convertible bond pricing by least squares Monte Carlo simulation. Section 3 derives the equation of dynamic credit spread. Section 4 is the empirical part, including the effect of dynamic credit spread and the comparison of price obtained by assuming whether the conversion price changes or not. Finally, Section 5 concludes the paper.

\section{Basic Framework of Convertible Bond Pricing by LSM}

Besides the common debt, convertible bonds are embedded with many options, such as conversion option, call option, put option, and option to lower the conversion price. So, we should compare the value of these options comprehensively when pricing the convertible bonds. At the expiration, the final boundary can be $V=\max \left(n S_{T}, C_{T}\right)$.

Every moment before the maturity of the convertible bond, investors and issuers will gamble over the benefit. Investors will maximize the value of convertible bonds, while the issuer will minimize the value of convertible bonds from exercising the call option. To make it clear, we use Table 1 to show the rules of option exercise.

The basic framework of convertible bonds pricing by LSM when the credit risk is static is as follows.

(1) Considering the stock volatility is one of the important parameters affecting stock path, we assume that the stock price follows the stochastic volatility model presented by Heston [14]:

$$
\begin{aligned}
& d S_{t}=S_{t}\left(r_{f}-q\right) d t+S_{t} \sqrt{v_{t}} d W, \\
& d v_{t}=\kappa\left(\bar{v}-v_{t}\right) d t+\sqrt{v_{t}} \sigma_{v} d W_{v},
\end{aligned}
$$

where $r_{f}$ is the risk-free interest rate, $q$ is the dividend yield of the underlying stock, $v_{t}$ is the stochastic volatility of $S_{t}$ and is modeled by the second equation of (1), $\kappa$ is the mean reversion coefficient of $v_{t}, \bar{v}$ is the long-term mean reversion level of $v_{t}$, and $\sigma_{v}$ is the volatility of $v_{t}, W$ and $W_{v}$ are both Wiener processes.

We split the duration of convertible bonds into $N$ sections on average and assume that the convertible bonds can only be exercised at these discrete times. We can generate random numbers by Monte Carlo simulation and then get $N_{u}$ paths from the Heston model. Then, the stock price matrix is obtained.

(2) Applying the optimal stopping theory, we compare the value of continuation and immediate exercise. If the latter one is bigger, then we get the stopping time denoted by $J$ and stopping value denoted by $M_{i}^{N_{u}}$.
(3) We assume $(\Omega, F, P)$ to be the complete probability space and assume $[0, T]$ to be the finite time horizon. $\mathfrak{R}=$ $(\Re)_{i=0, \ldots, N}$ is defined to be the augmented filtration generated by the actual market performance, and $\Re_{0} \subset \Re_{1} \subset \cdots \subset \mathfrak{R}_{N}$. The state variable $S$ is the simulated stock price, from which we calculate the cash flow $C(\omega, j)$ on the path $\omega$ at time $j$ and the temporary optimal stopping value $M_{i}^{N_{u}}$. Then we take the expectation of the cash flows $C(\omega, j)$ discounted by the risky interest rate $r(\omega, s)$, and get the value of continuation $Y(\omega ; t)$ as follows:

$$
Y(\omega ; t)=E_{\mathrm{Q}}\left[\sum_{j=t+1}^{N} \exp \left(-\int_{t}^{j} r(\omega, s) d s\right) C(\omega, j) \mid \Re\right] .
$$

(4) The least square regression process is as follows. We put the value of continuation to be the dependent variable $Y$ and the underlying stock price to be the independent variable $X$, and Laguerre polynomials are chosen to be the basis function to make the least square regression. The procedure to get the estimated value of $Y$ can be described by the following equations:

$$
\begin{gathered}
Y_{0}(X)=\exp \left(-\frac{X}{2}\right), \\
Y_{1}(X)=\exp \left(-\frac{X}{2}\right)(1-X), \\
Y_{2}(X)=\exp \left(-\frac{X}{2}\right)\left(1-2 X+\frac{X^{2}}{2}\right), \\
\widehat{Y}(\omega ; t)=\sum_{j=0}^{2} a_{j} Y_{j}(X) .
\end{gathered}
$$

(5) Compare $\widehat{Y}(\omega ; t)$ with the conversion value, call value, and the put value on the basis of the exercise rules of convertible bonds. If $\hat{Y}(\omega ; t)$ is bigger, then the optimal stopping value remains the same; if $\widehat{Y}(\omega ; t)$ is smaller, then we get the new stopping time $t$ and the new stopping value $M_{i}^{N_{u}}$.

(6) The convertible bond can be valued by discounting each $M_{i}^{N_{u}}$ back to time $t=0$ with the risky interest rate, and averaging over all paths:

$$
V=\frac{1}{N_{u}} \sum_{j=1}^{N_{u}} \exp \left(-\int_{0}^{j} r(\omega, s) d s\right) M_{j}
$$

It is worth noticing that not all values of continuation are estimated by the Laguerre polynomials. To increase the estimated accuracy, the following three conditions must be excluded.

(a) When the call provisions have been triggered, no matter how big the value of continuation is, the convertible bonds will be exercised and terminated, so the value of continuation does not need to be estimated. 
TABLE 1: Rules of option exercise in convertible bonds.

\begin{tabular}{|c|c|c|c|}
\hline Case & Payoff & Rules & $\begin{array}{c}\text { Exercise } \\
\text { restriction }\end{array}$ \\
\hline Conversion & $n_{t} S_{t}$ & $\begin{array}{l}n_{t} S_{t}>F(\omega, t) \\
\text { and } P_{t} \leq n_{t} S_{t}\end{array}$ & $\begin{array}{c}t \in \Omega_{\text {conv }} \\
t \in \Omega_{\text {put }} \cap \Omega_{\text {conv }}\end{array}$ \\
\hline Call & $P_{t}$ & $\begin{array}{c}P_{t}>F(\omega, t) \\
\text { and } n_{t} S_{t} \leq P_{t}\end{array}$ & $\begin{array}{c}t \in \Omega_{\text {put }} \\
t \in \Omega_{\text {put }} \cap \Omega_{\text {conv }}\end{array}$ \\
\hline Put & $C_{t}$ & $\begin{array}{c}F(\omega, t)>C_{t} \\
\text { and } C_{t}>n_{t} S_{t}\end{array}$ & $\begin{array}{c}t \in \Omega_{\text {call }} \\
t \in \Omega_{\text {call }} \cap \Omega_{\text {conv }}\end{array}$ \\
\hline Forced conversion & $n_{t} S_{t}$ & $\begin{array}{c}F(\omega, t)>C_{t} \\
\text { and } C_{t}<n_{t} S_{t}\end{array}$ & $\begin{array}{c}t \in \Omega_{\text {call }} \\
t \in \Omega_{\text {call }} \cap \Omega_{\text {conv }}\end{array}$ \\
\hline
\end{tabular}

(b) When the put provisions have been triggered, and the call value is smaller than the discounted value of the minimum payoff $V_{\min }$ until the maturity, the call action will not be exercised definitely. So, the value of continuation does not need to be estimated.

(c) When the call provisions and the put provisions have not been triggered, if the conversion value is smaller than the discounted value of the minimum payoff $V_{\min }$ until the maturity, the conversion action will not be exercised definitely. So, there is no need to estimate the value of continuation, where $V_{\min }$ is the discounted value of the call value until maturity.

\section{The Dynamic Credit Risk Model}

Currently, there are two main methods to describe the dynamic credit risk. The first one is the two and a half model of Davis and Lischka [5], who assumed that the hazard rate obeys a Brownian motion. The second one is of Huang et al. [15], who assume the credit spread to be linked with the asset value of the company.

In this paper, we describe the credit risk to be the dynamic credit spread linked with the stock price, because the credit risk is mostly affected by the stock price. Moreover, the conversion price can be the benchmark of the stock price, and then we can derive the equation of dynamic credit spread $r_{c}$ as follows:

$$
r_{c}=r_{m c}\left(\frac{X}{S}\right)^{\eta}
$$

where $r_{m c}$ denotes the average credit spread, $X$ is the conversion price, and $S$ is the stock price. The equation indicates that when $S>X$, the credit spread will decrease; when $S<X$, the credit spread will increase. $\eta$ denotes the adjustment speed. Finally, the risky interest rate $r(\omega, t)$ in the last section can be written to be

$$
r(\omega, t)=r_{f}+r_{m c}\left(\frac{X}{S}\right)^{\eta}
$$

\section{Empirical Research}

To test the performance of our model, we consider ICBC convertible bond, one of the largest convertible bonds issued in China, to do the empirical study. We adopt 146 weekly
TABLE 2: ICBC convertible bond.

\begin{tabular}{lc}
\hline Convertible bond & ICBC convertible bond \\
\hline Issue date & 2010.8 .31 \\
Time horizon & 6 \\
Face value & 100 \\
Coupon (\%) & $0.5,0.7,0.9,1.1,1.4,1.8$ \\
Call value till maturity & 105 \\
The first conversion price & 4.2
\end{tabular}

2010.11.26, adjusted to 4.16 2010.12.27, adjusted to 4.15

Change of conversion price $\quad$ 2011.6.15, adjusted to 3.97 2012.6.14, adjusted to 3.77 2013.6.26, adjusted to 3.53

In 30 consecutive trading days,

Reset clause the closing stock price is smaller than $80 \%$ of conversion price in 15 trading days.

In 30 consecutive trading days,

Call on condition the closing stock price is bigger than $130 \%$ of conversion price in 15 trading days.

Call value

Face value plus the accrued interest

Put on condition

When the use of capital is changed

Put value

Face value plus the accrued interest

data from August 12, 2011, to January 3, 2014, obtained from CSMAR. The information of ICBC convertible bond is in Table 2.

Before pricing we first need to estimate the related parameters. We get the term structure of risk-free interest rate based on cubic polynomial spline function using 15 treasury bonds traded in Shanghai Exchange. By minimizing the sum of squared errors between the market price and the simulated price of the underlying stock we get the three parameters in Heston's stochastic volatility model: $\sigma_{v}=0.40, \kappa=1.3$, and $\bar{v}=0.04$. We employ the estimation result obtained by Zheng and Lin [16] to be China's average credit spread; that is, $r_{m c}=0.98$. 


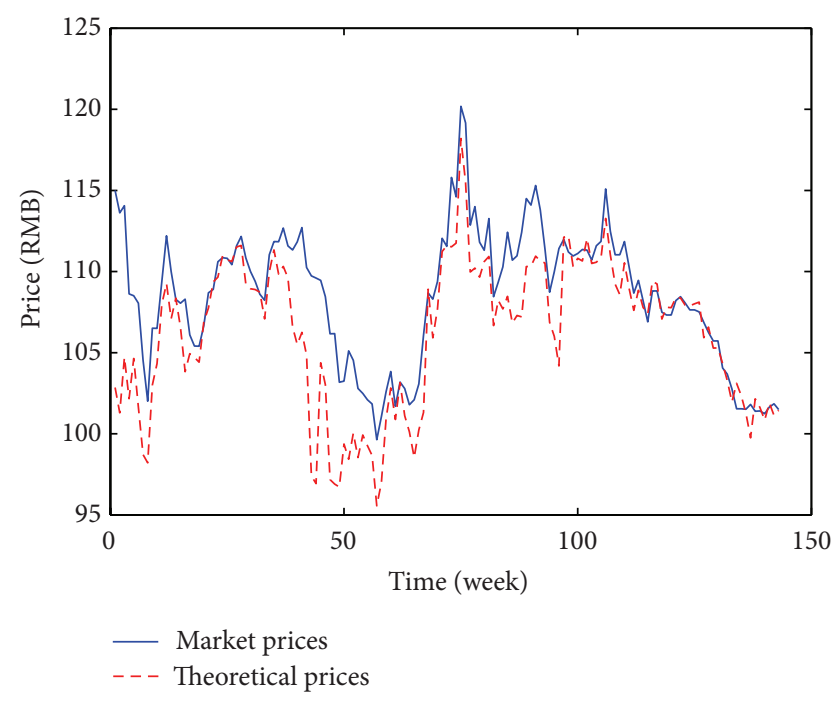

FIGURE 1: Comparison of the theoretical and market prices of ICBC convertible bond.

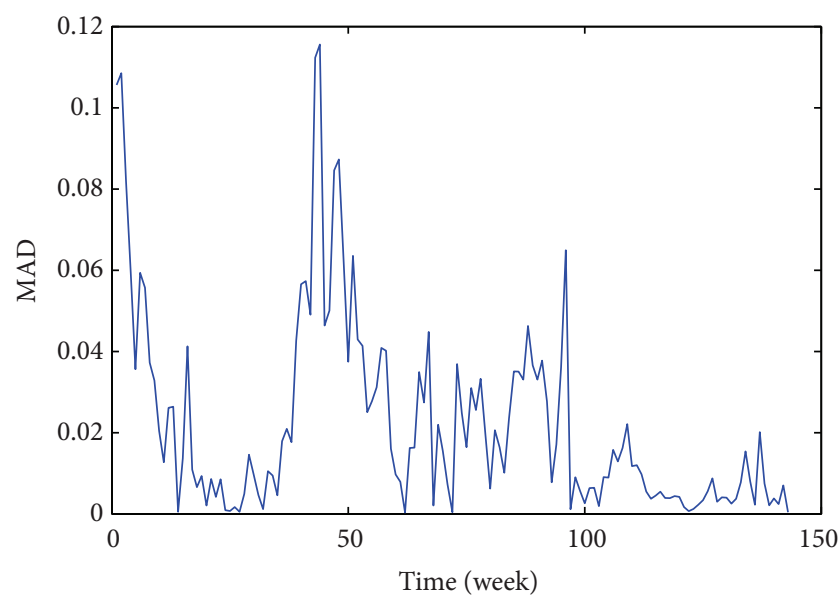

FIGURE 2: The relative deviation (AD) of ICBC convertible bond.

4.1. Pricing Results with Static Credit Risk. We first assume that the credit risk is static and get 5000 paths of the stock price by LSM. Then we get the theoretical prices of ICBC convertible bond using our pricing framework. Figure 1 is the comparison of the theoretical prices and market prices.

From Figure 1 we can see that the tendencies of the two lines fit well in the long run, so we can use this price framework to forecast market price of convertible bond and make investment decision. On the other hand, the market price is a little higher than the theoretical price, so ICBC convertible bond is a little overpriced.

We also define the variable $\mathrm{AD}$ to be the absolute deviation of the theoretical price from the market price as follows:

$$
\mathrm{AD}_{i}=\frac{\left|V_{i}-\bar{V}_{i}\right|}{\bar{V}_{i}} .
$$

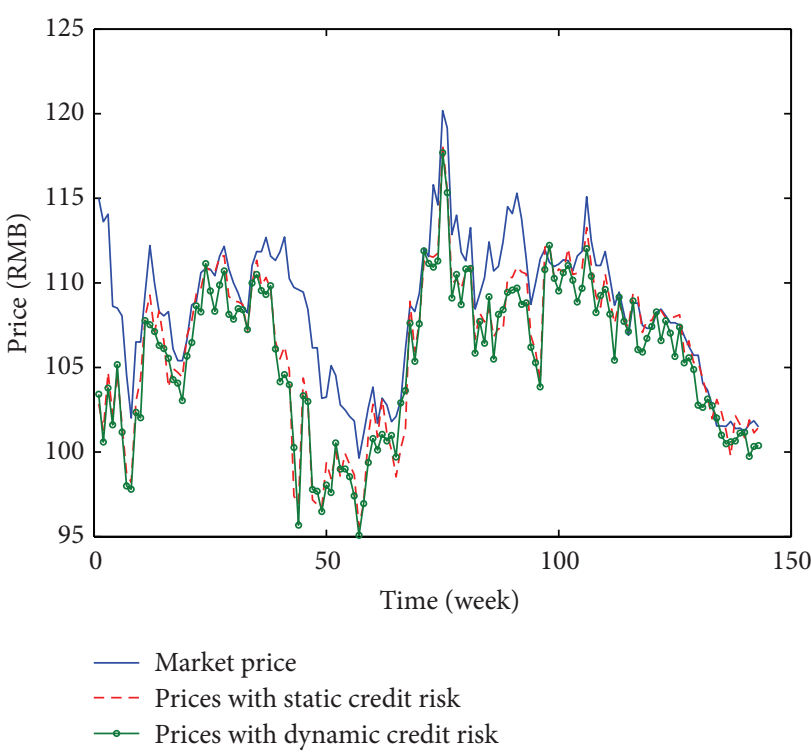

FIGURE 3: Comparison of theoretical prices with dynamic and static credit risk.

Then we get the figure of AD by Matlab and depict it in Figure 2.

The following mean absolute deviation MAD is defined to describe the integral result of our model:

$$
\mathrm{MAD}=\frac{1}{146} \sum_{i=1}^{146} \mathrm{AD}_{i}
$$

Through calculation, the mean absolute deviation of ICBC convertible MAD is $2.3 \%$, within $5 \%$, which demonstrates that the theoretical price obtained from our model can reflect market price.

4.2. Pricing Results Using Dynamic Credit Risk. In this section, we give the pricing results of ICBC convertible bond using the dynamic credit risk modeled by (6) and with $\eta=2$. We compare the market prices with the prices obtained from static credit risk and dynamic credit risk in Figure 3.

We can see from Figure 3 that the market price of the ICBC convertible bond is higher than the prices obtained from both the static and dynamic credit risk models, which means that the ICBC convertible bond is overestimated, resulting from the underestimation of credit risk. We can also see that the dynamic credit risk can reflect the real credit risk, since when the price of convertible bond goes downwards, the price obtained from dynamic credit risk is lower than those obtained from static credit risk. This implies that we should use dynamic credit risk to price convertible bonds.

4.3. Effect of Conversion Price. In the above empirical study we price the ICBC convertible bond based on changing conversion price $(\mathrm{CP})$ resulting from two issues of dividend. Though most Chinese companies change conversion price when issuing dividend, international companies' conversion price does not change. So in this section we also give the 


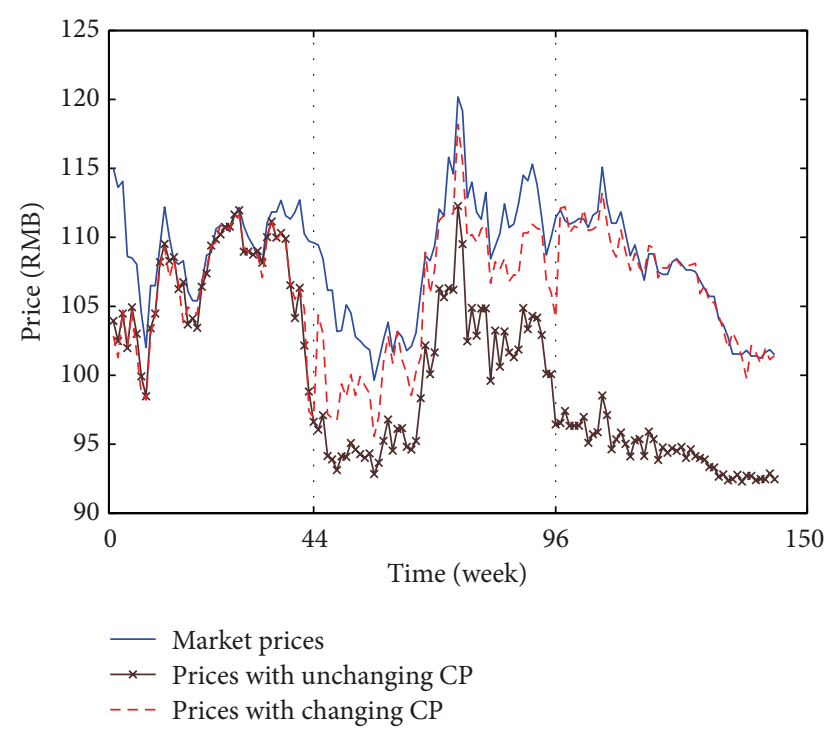

FIGURE 4: Pricing results without changing the conversion price.

prices of ICBC convertible bond assuming that the conversion price does not change. The pricing results together with those obtained from changing conversion price are shown in Figure 4.

Figure 4 indicates that, compared with the prices with changing CP obtained in Section 4.1, the obtained prices with unchanging $\mathrm{CP}$ have two jumps at time $t=44$ and $t=$ 96, just after the CP changed. This demonstrates that when the company issues dividend the effect of unchanging $\mathrm{CP}$ is significant. This can be explained by the fact that when there is an issue of dividend investors of China's convertible bonds will have an expectation of price decline which will affect the payoff of convertible bonds eventually. Therefore, Chinese companies of convertible bonds are suggested to change $\mathrm{CP}$ when issuing dividend. That is, we cannot copy the international experience of unchanging $\mathrm{CP}$.

\section{Conclusion}

This paper studies the pricing of convertible bonds with dynamic credit risk using least squares Monte Carlo method. We employ the dynamic credit spread changing with stock price. In empirical study, our model is proved to be effective and the comparison test demonstrates that the dynamic credit risk is important in convertible bond pricing. The price obtained from dynamic credit risk can reflect the real credit risk. Thus, the potential risk resulting from the overestimation of convertible bonds cannot be neglected by the investors. In addition, we also study the empirical effect of changing the conversion price when the issuer distributes dividend. Consequently, the unchanged conversion price will lead to an unreasonable price. So, China's market is not mature enough to keep the conversion price constant just like international markets.

\section{Conflict of Interests}

The authors declare that there is no conflict of interests regarding the publication of this paper.

\section{Acknowledgment}

This work was supported by the National Natural Science Foundation of China (nos. 71271015 and 70971006).

\section{References}

[1] J. E. Ingersoll Jr., "A contingent-claims valuation of convertible securities," Journal of Financial Economics, vol. 4, no. 3, pp. 289321, 1977.

[2] M. J. Brennan and E. S. Schwartz, "Convertible bonds: valuation and optimal strategies for call and conversion," The Journal of Finance, vol. 32, no. 5, pp. 1699-1715, 1977.

[3] J. J. McConnell and E. S. Schwartz, "LYON taming," The Journal of Finance, vol. 41, no. 3, pp. 561-576, 1986.

[4] M. J. Brennan and E. S. Schwartz, "Analyzing convertible bonds," Journal of Financial and Quantitative Analysis, vol. 15, pp. 907-929, 1980.

[5] M. Davis and F. R. Lischka, "Convertible bonds with market risk and credit risk," Working Paper, Tokyo-Mitsubishi International, 1999.

[6] F. A. Longstaff and E. S. Schwartz, "Valuing American options by simulation: a simple least-squares approach," Review of Financial Studies, vol. 14, no. 1, pp. 113-147, 2001.

[7] M. Moreno and J. F. Navas, "On the robustness of least-squares Monte Carlo (LSM) for pricing American derivatives," Review of Derivatives Research, vol. 6, no. 2, pp. 107-128, 2003.

[8] L. Stentoft, "Convergence of the least squares Monte Carlo approach to American option valuation," Management Science, vol. 50, no. 9, pp. 1193-1203, 2004.

[9] S. Crépey and A. Rahal, "Pricing convertible bonds with call protection," Journal of Computational Finance, vol. 15, no. 2, pp. 37-75, 2011.

[10] M. Ammann, A. Kind, and C. Wilde, "Simulation-based pricing of convertible bonds," Journal of Empirical Finance, vol. 15, no. 2, pp. 310-331, 2008.

[11] K. Tsiveriotis and C. Fernandes, "Valuing convertible bonds with credit risk," The Journal of Fixed Income, vol. 8, no. 2, pp. 95-102, 1998.

[12] D. Duffie and K. J. Singleton, "Modeling term structures of defaultable bonds," Review of Financial Studies, vol. 12, no. 4, pp. 687-720, 1999.

[13] E. Ayache, P. A. Forsyth, and K. R. Vetzal, "Valuation of convertible bonds with credit risk," The Journal of Derivatives, vol. 11, no. 1, pp. 9-29, 2003.

[14] S. L. Heston, "A closed-form solution for options with stochastic volatility with applications to bond and currency options," Review of Financial Studies, vol. 6, no. 2, pp. 327-343, 1993.

[15] J. G. Huang, S. C. Yang, and X. Feng, "Valuation of convertible bond with dynamic credit risk," Mathematical Statistics and Management, vol. 27, no. 6, pp. 1108-1116, 2008.

[16] Z. L. Zheng and H. Lin, "Estimation of the default risk premium in China," Securities Market Herald, vol. 13, no. 6, pp. 41-44, 2003. 


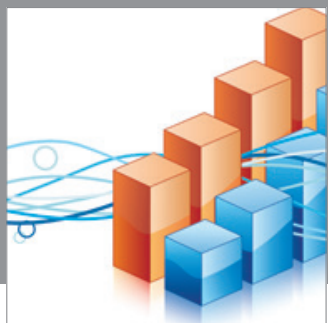

Advances in

Operations Research

mansans

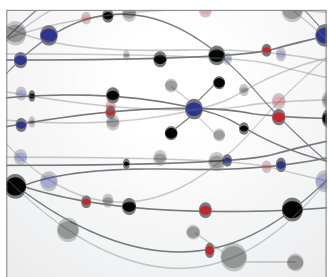

The Scientific World Journal
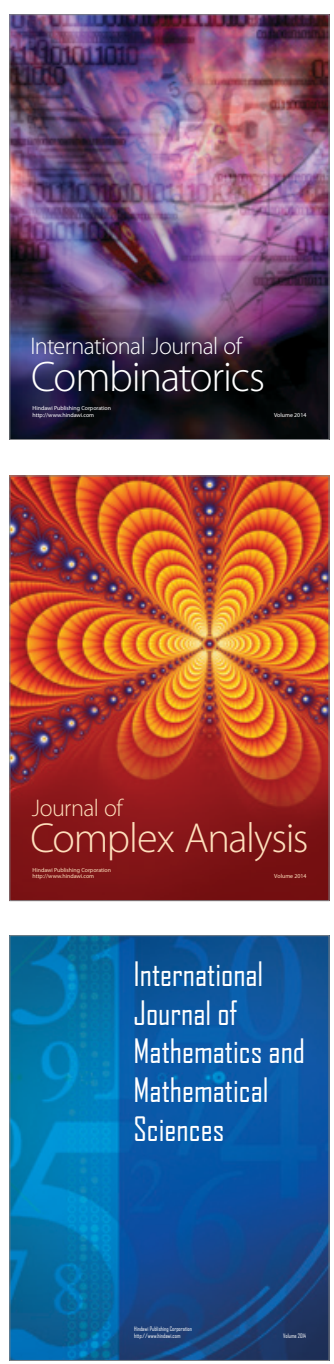
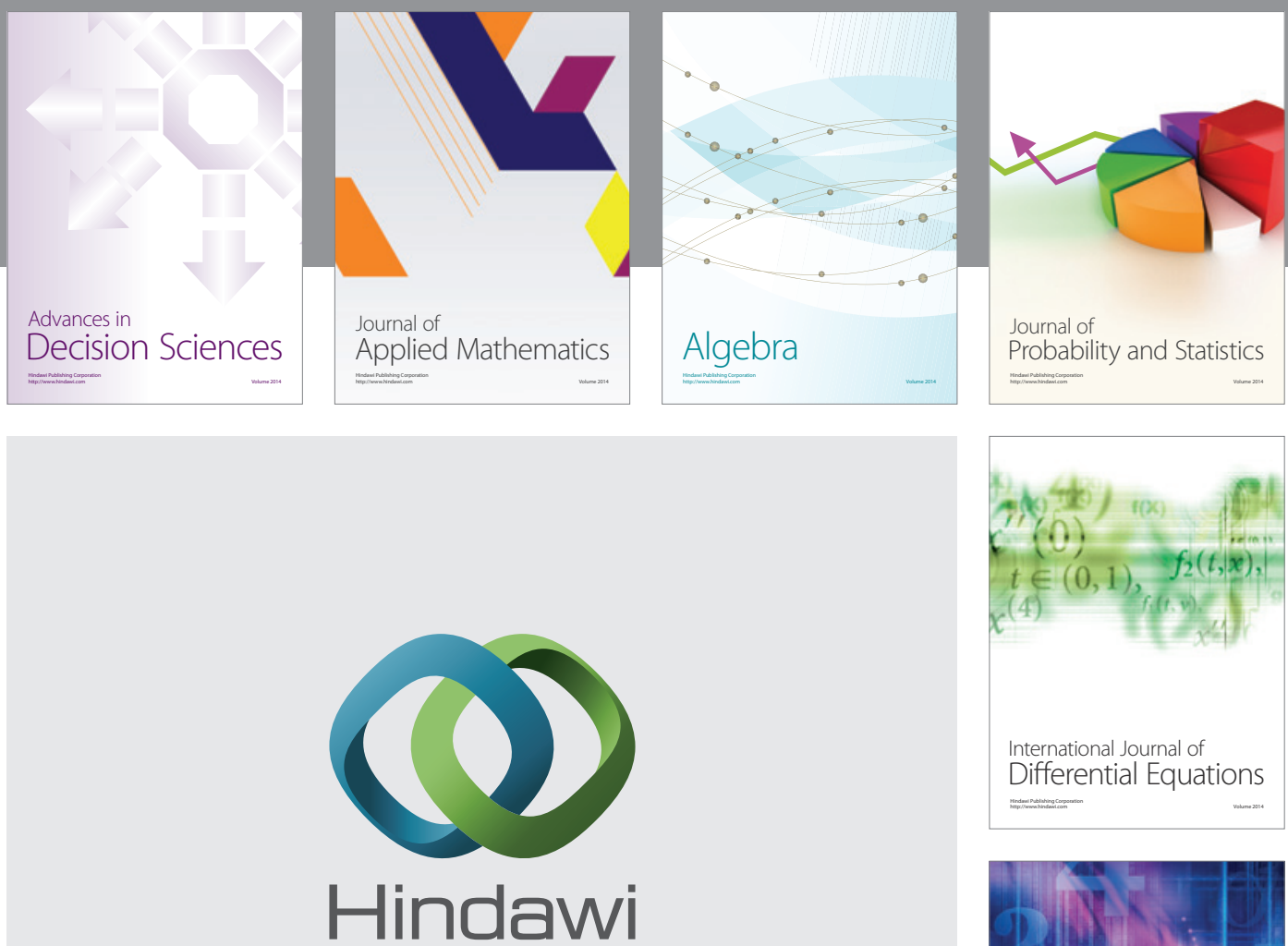

Submit your manuscripts at http://www.hindawi.com
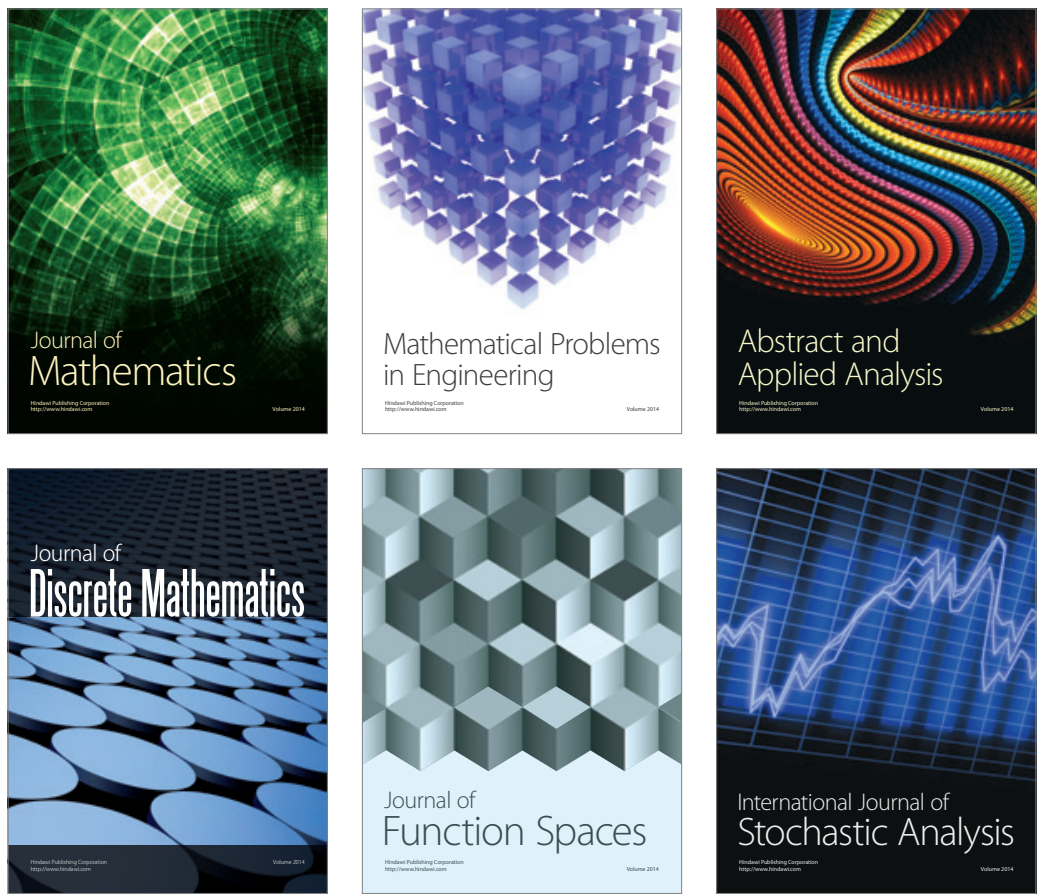

Journal of

Function Spaces

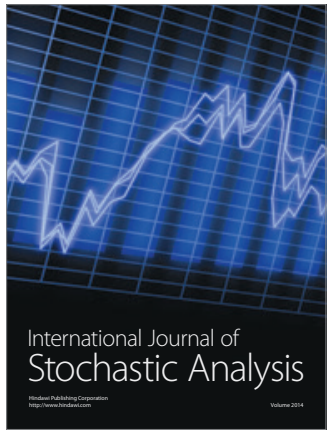

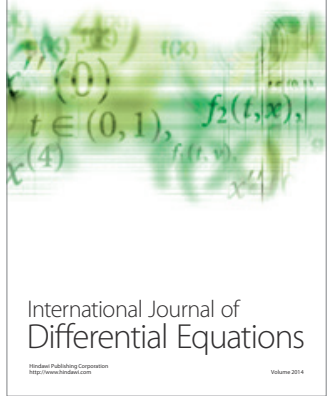
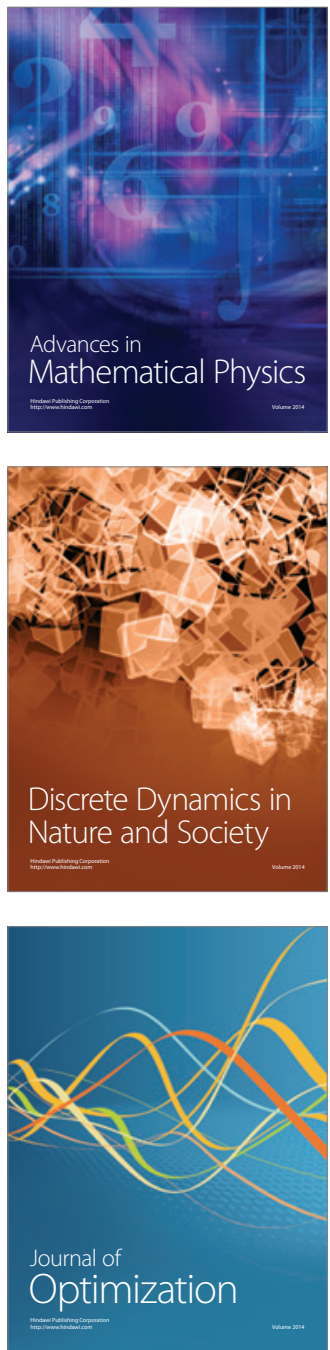